weeks, and atrophic gastritis could not have developed so rapidly. Nevertheless, this possibility could not be excluded in other cases (Nos. 4, 5, 7, 8, and 10) in which the decrease started gradually after a period of months. Gastric biopsy suggested atrophic gastritis in Cases 5 and 10.

A decrease in maximal acid output may perhaps be an explanation for the prolonged remissions observed in some cases of duodenal ulcer. The spontaneous decrease seen in patients with duodenal ulcer suggests that the larger parietal cell mass in these patients is probably acquired and not inherited.

A decrease in acid ouput in patients with duodenal ulcer after prolonged administration of anticholinergic drugs has been attributed to the drug (Hunt and Wales, 1966) or to a spontaneous fluctuation in parietal cell mass independently of the drug (Kaye, Beck, Rhodes, and Sweetman, 1969). Since a spontaneous decrease in maximal acid output is not uncommon in patients with duodenal ulcer, as shown by this study, caution should be exercised before attributing a decrease in acid output to the drug administered.
Part of this study was aided by a grant from B.Y.L. Nair Charitable Hospital and T.N.M.C. Research Society.

\section{References}

Beveridge, B. R., Bannerman, R. M., Evanson, J. M., and Witts, L. J. (1965). Quarterly fournal of Medicine, 34, 145.

Card, W. I., and Marks, I. N. (1960). Clinical Science, 19, 147.

Crosby, W. H., and Kugler, H. W. (1957). American fournal of Digestive Diseases, 2,236

Davidson, W. M. B., and Markson, J. L. (1955). Lancet, 2, 639.

Desai, H. G., Borkar, A. V., and Jeejeebhoy, K. N. (1967). Gastroenterology, 53,712 .

Desai, H. G., Mehta, B. C., Borkar, A. V., and Jeejeebhoy, K. N. (1967) Indian fournal of Medical Research, 55, 1051.

Desai, H. G., Mehta, B. C., Borkar, A. V., and Jeejeebhoy, K. N. (1968). Gut, 9,91 .

Desai, H., G., Zaveri, M. P., and Antia, F. P. (1970a). Gastroenterology, $59,701$.

Desai, H. G., Zaveri, M. P., and Antia, F. P. (1970b). Indian fournal of Medical Research, 58, 202 .

Desai, H. G., Zaveri, M. P., and Antia, F. P. (1971). Unpublished.

Hunt, J. N., and Wales, R. C. (1966). British Medical fournal, 2, 13.

Kaye, M. D., Beck, P., Rhodes, J., and Sweetman, P. M. (1969). Gut, 10,774 .

Kothari, M. L., et al. (1969). Gut, 10, 71.

Waterfall, W. (1969). British Medical fournal, 4, 459.

Winship, D. H., and Ellison, E. H. (1967). Lancet, 1, 1128.

\title{
Termination of Pregnancy by the Intrauterine Insertion of Utus Paste
}

\author{
S. V. SOOD
}

British Medical fournal, 1971, 2, 315-317

\section{Summary}

Utus paste was used to induce abortion in 83 women. It was successful in all but two. Pain was a prominent symptom in many cases. Complications included three cases of septicaemia and one of perforation of the uterus leading to death. This experience shows the complications of abortion induced by Utus paste to be too serious to justify its further use.

\section{Introduction}

Medicated soft soaps for the induction of abortion by intrauterine injection were invented in Germany in the 1930s. Their use spread to America and later to Britain after Browne (1946) and Barnes (1946) had drawn attention to them. This has been the method of choice in St. Helier Hospital, Carshalton, for the past 20 years (Lachelin and Burgess, 1968).

Abortifacient pastes have been in and out of favour ever since they were first used. Large-scale studies are, unfortunately, not available for reliable evidence and fuller assessment of their usefulness. Engelmann (1932a, 1932b) studied cases of criminal abortion in which pregnancy was terminated with Interruptin and he noted 12 deaths due to fat embolism and five due to air embolism. Weilerstein (1944) reported two cases in which perforation followed injection of the paste, with infection and subsequent death.

West Middlesex Hospital, Isleworth, Middlesex

S. V. SOOD, F.R.C.S.ED., M.R.c.o.G., Senior Gynaecological Registrar
Dutra et al. (1950) reported on medicolegal investigations of seven cases of criminal abortion with four deaths. They described the postmortem findings and conducted experiments on rabbits, and showed that intravenous injections of the paste proved immediately fatal with focal haemorrhages in lungs. Subcutaneous infections caused necrosis of skin, subcutaneous tissues, and adjacent skeletal muscles, very similar to the necrosis of the uterine wall observed in one of the four fatal cases. Williams et al. (1955), in a series of 32 cases, reported one case each of pulmonary embolism, pulmonary oedema with intravascular haemolysis and haemoglobinuria, shock and renal damage, and haemoglobinuria with very mild jaundice. There were two cases of pelvic infection. These complications led them to abandon this method.

Döderlein, in a letter to Riddell (1932), cast some doubt on the accuracy of the causes of death in cases recorded owing to the paucity of pathological and microscopical evidence taken at necropsy.

Barns (1947) reviewed 71 cases. He described six cases of "pyrexia reaching morbidity standard" and "heavy blood loss" after abortion in four cases. Lachelin and Burgess (1968) were enthusiastic and reviewed 182 cases, reporting that not only was abortion successful in every case but there were no serious complications. Diggory (1969) reported on 59 cases of termination by utus paste-one patient had a severe intrauterine infection with rigors, three patients needed a second injection of paste, and in two cases hysterotomy had to be undertaken as abortion did not occur.

During 1968 and 1969 a commercially available Utus paste was used for induction of abortion at the West Middlesex Hospital in a tocal of 83 cases.

\section{Technique}

The patient was admitted to hospital and prepared for a vaginal operation. The premedication was ordered by the anaesthetist 
and administered an hour before the operation. In about $20 \%$ of cases a general anaesthetic was necessary. The patient was placed in the lithotomy position and the vulva and vagina were cleansed with a 1:800 solution of Cetridine before applying sterile towels. A pelvic examination was undertaken after catheterizing the bladder, to confirm the diagnosis, to determine the position of the uterus, and to exclude any pelvic infection. The cervix was grasped with a sponge-holding forceps and the cannula of the assembled apparatus was introduced into the uterus through the cervical canal without previous dilatation and Utus paste was injected slowly at the rate of $2 \mathrm{ml} /$ minute between the gestation sac and the uterine wall.

If contractions had not started at the end of 24 hours an intravenous Syntocinon (oxytocin) drip of 20 units/litre was begun; if this failed to excite uterine contractions a further injection of Utus paste was made. Evacuation of the uterus by dilatation and blunt curettage was undertaken in all cases in which abortion occurred.

\section{Results}

Of the 83 patients $28(33 \%)$ were married and 28 were parous. An intravenous Syntocinon infusion was used in $13(16 \%)$ cases. A second injection of Utus paste was needed in two cases.

Factors Influencing Induction-Abortion Interval.-(1) Volume of Utus paste: the volume injected varied from one patient to another; this did not affect the induction-abortion interval (I.A.I.) (see Table). (2) Parity: $55(66 \%)$ were nulliparous;

Volume of Utus Paste Injected

\begin{tabular}{cc|c|c|c}
\hline \multicolumn{2}{c|}{ Patients } & $\begin{array}{c}\text { Volume/Week } \\
\text { of Gestation }\end{array}$ & $\begin{array}{c}\text { Average I.A.I. } \\
\text { in Hours }\end{array}$ & Range in Hours \\
\cline { 3 - 4 } $32(39 \%)$ &. & $1.0 \mathrm{ml}$ & $36 \cdot 0$ & $18-96$ \\
$12(14 \%)$ & $\cdots$ & $1.5 \mathrm{ml}$ & 28.5 & $17-44$ \\
$35(42 \%)$ & $\cdots$ & $2 \cdot 0 \mathrm{ml}$ & $34 \cdot 6$ & $18-72$ \\
$4(5 \%)$ & $\cdots$ & $2.5 \mathrm{ml}$ & $47 \cdot 0$ & $20-70$ \\
\hline
\end{tabular}

parity varied from $0+0$ to $5+0$; no significant difference existed between parous and nulliparous patients. (3) Gestation: the duration of pregnancy varied from 10 to 20 weeks; there was no correlation between the length of gestation and inductionabortion interval.

Length of Stay in Hospital.-The length of stay varied from 3 to 33 days. There was no relation between the period of the gestation and the length of stay. The average stay was 7.5 days.

\section{COMPLICATIONS}

Pyrexia.-Twelve patients had pyrexia of $100^{\circ} \mathrm{F}\left(37 \cdot 8^{\circ} \mathrm{C}\right)$ for over three days or more requiring antibiotic therapy.

Urinary Tract Infection.-This occurred in six cases. This complication would probably have been avoided by not catheterizing the bladder before operation.

Irregular Vaginal Bleeding.-Five patients complained of irregular bleeding after discharge and had to be readmitted for dilatation and curettage. Examination of the curettings showed that this was due to retained products.

Cervical Trauma.-This occurred in two cases. On one occasion a single stitch was necessary in a 27 -year-old multipara but in the other case a more extensive tear occurred in an 18year-old nulliparous patient and needed seven sutures.

Haemorrhage.-The average loss in all cases was between 100 and $150 \mathrm{ml}$. This included blood loss at abortion and subsequent evacuation of the uterus. Excessive blood loss of at least 1 litre occurred at evacuation of the uterus in the case of a 16-year-old single para $0+0$ at 16 weeks' gestation. Her haemoglobin level dropped from 89 to $53 \%$ and she was treated with "total dose" iron dextran infusion.
Failed Abortion.-This occurred in two cases when abdominal hysterotomy had to be undertaken. The first patient was a 21-year-old single nullipara at 16 weeks' gestation and the second was a 24 -year-old married para $1+0$ also at 16 weeks' gestation.

Uterine Infection without Other Complications.-One patient, a 29 -year-old para $3+1$ at 14 weeks' gestation, developed pyrexia of $102^{\circ} \mathrm{F}\left(38.9^{\circ} \mathrm{C}\right)$, lower abdominal pain, and uterine tenderness, and was thought to have pelvic peritonitis. A high vaginal swab showed a profuse growth of Escherichia coli sensitive to ampicillin. She responded well to antibiotic therapy.

Septicaemia.-This complication occurred in the following three cases. In 1,300 cases of termination of pregnancy reviewed at the West Middlesex Hospital septicaemia occurred only in those patients given Utus paste.

Case 1.-A 15-year-old schoolgirl had her pregnancy terminated at 14 weeks by insertion of $25 \mathrm{ml}$ of Utus paste. She aborted on the next day, and subsequently developed a pyrexia of $104^{\circ} \mathrm{F}\left(40^{\circ} \mathrm{C}\right)$ with tachycardia and rigors, and became very confused. The uterus was very tender and there was a foul-smelling vaginal discharge. Both a high vaginal swab and blood culture grew Proteus, E. coli, and Streptococcus faecalis and all were sensitive to ampicillin. She was initially treated with ampicillin and kanamycin, and later Septrin was substituted for kanamycin. She was very ill over the next 10 days. After pyrexia had subsided the uterus was evacuated on the 12th day, and retained products of conception were obtained. She spent 19 days in hospital.

Case 2.-A 19-year-old single girl had termination of pregnancy carried out by the insertion of $20 \mathrm{ml}$ of utus paste at 16 weeks. She aborted on the next day and her uterus was evacuated the same day. A few hours later she developed lower abdominal pain, tachycardia, pyrexia of $103^{\circ} \mathrm{F}\left(39.4^{\circ} \mathrm{C}\right)$ and rigors. Blood culture grew Proteus which was sensitive to ampicillin. The urine was sterile and high vaginal swab showed a profuse growth of $E$. coli, also sensitive to ampicillin. She responded quickly to ampicillin therapy and was apyrexial by the fourth day.

Case 3.-The pregnancy of a 28 -year-old married woman, para $4+0$, was terminated at 16 weeks by the insertion of $30 \mathrm{ml}$ of Utus paste. She aborted 20 hours after and her uterus was later evacuated. On the third postoperative day she developed tachycardia, rigors, and pyrexia of $103^{\circ} \mathrm{F}\left(39 \cdot 4^{\circ} \mathrm{C}\right)$. She was treated with ampicillin, and later with ampicillin and Septrin. Repeated blood cultures showed growth of Str. faecalis and bacteroides spores. High vaginal swab and midstream specimen of urine yielded cultures of $E$. coli. She became apyrexial on the 13th postoperative day and subsequently remained well.

Perforation of Uterus, Pelvic Infection, and Death.-This happened in the following case.

A 31-year-old married woman had her pregnancy terminated by the intrauterine insertion of $30 \mathrm{ml}$ of Utus paste at 16 weeks' gestation. Preoperatively her condition was good and her haemoglobin was $77 \%$. She aborted after 20 hours and her uterus was evacuated four hours later. Next day she developed a pyrcxia of $100^{\circ} \mathrm{F}\left(37.8^{\circ} \mathrm{C}\right)$ and she had a tender and bulky uterus the size of a 12 -week pregnancy. Ampicillin therapy was begun and she became apyrexial three days later and remained apyrexial until her discharge on the sixth postoperative day, when she appeared fit though her uterus was bulky and not tender on pelvic examination. At home she complained of pain in both loins and in the lower abdomen and also frequency of micturition. Her general practitioner found she had suprapubic tenderness and tachycardia and treated her with sulphonamides and antibiotics. She remained apyrexial but had persistent tachycardia. She died on the seventh day after discharge from hospital. At necropsy a rupture of the right side of the fundus of the uterus was found involving an area of $1 \frac{1}{2}$ in $(3.8 \mathrm{~cm})$. The walls of the uterus were congested and there was thick green pus in the cavity and around the necrotic edges of the rupture. The omentum had localized the infection to around the uterus and the right Fallopian tube. The kidneys were oedematous but microscopically normal. The other organs of the body showed no gross abnormality. 


\section{Discussion}

Termination of pregnancy with abortifacient paste appears at first to be a satisfactory method. The points in its favour are ease of insertion, usually without a general anaesthetic, and the possibility of evacuating the uterus up to 20 weeks of gestation without opening the abdomen. Lachelin and Burgess (1968) claimed that there is no need for routine curettage, but this was done in the present series. The pain during abortion, in my opinion, is much greater than the pain of a spontaneous abortion. However, the complications which might occur are not rare and often are severe and even fatal. In our experience this method has proved so unsatisfactory that it has been abandoned.

I wish to thank all the consultants in the department of obstetrics and gynaecology for permission to report on cases under their care.

\section{References}

Barnes, J. (1946). Practitioner, 156, 56.

Barns, H. H. F. (1947). Lancet, 2, 825.

Browne, F. J. (1946). Antenatal and Postnatal Care, 6th edn., p. 337. London, Churchill.

Diggory, P. L. C. (1969). Lancet, 1, 873.

Dutra, F. R., Cleveland, F. P., and Lyle, H. P. (1950). Fournal of the American Medical Association, 143, 865.

Engelmann, F. (1932). Deutsche medizinische Wochenschrift, 58, 166.

Engelmann, F. (1932). Zentralblatt für Gynäkologie, 56, 119.

Lachelin, G. C. L., and Burgess, D. E. (1968). Fournal of Obstetrics and Gynaecology of the British Commonwealth, 75, 1173 .

Riddell, Lord (1932). Fournal of Obstetrics and Gynaecology of the British Empire, 39, 1.

Weilerstein, R. W. (1944). Fournal of the American Medical Association, $125,205$.

Williams, G. F., Danino, E. A., and Davies, V. J. (1955). Fournal of Obstetrics and G.naecology of the British Empire, 62, 585.

\section{MEDICAL MEMORANDA}

\section{Heparin-treated Haemolytic- Uraemic Syndrome Simulating Fabry's Disease}

\author{
G. H. HALL, R. A. CALDWELL, C. SHALDON, \\ P. G. BISSON
}

\section{British Medical fournal, 1971, 2, 317-318}

Giromini and Laperrouza (1969) reported a case of the haemolytic-uraemic syndrome with intractable malignant hypertension requiring bilateral nephrectomy. We here report a similar case where prednisone and heparin produced only temporary improvement and may have been responsible for unusual histological changes. Renal transplantation was carried out a year later.

\section{Case Report}

In July 1969 a boy aged 12 developed a swelling of the face, vomiting, abdominal pain, and a purpuric rash and passed dark scanty urine. Examination at Torbay Hospital showed anaemia (Hb $10.0 \mathrm{~g}$ falling to $6.0 \mathrm{~g} / 100 \mathrm{ml}$ ), thrombocytopenia $\left(23,000 / \mathrm{mm}^{3}\right)$, and uraemia $(400 \mathrm{mg} / 100 \mathrm{ml})$. A presumptive diagnosis of haemolytic-uraemic syndrome was made, and on the patient's transfer to us the diagnosis was supported by a finding of 8 nucleated red cells per 100 white cells and numerous schistocytes in the blood film and the presence of methaemalbumin in the serum. Heparin (Piel and Phibbs, 1966) 20,000 units daily by continuous intravenous injection was started immediately. After six weeks this was increased to 24,000 units for a further four weeks. Renal biopsy could not therefore be performed at this stage. The uraemia was controlled by a high-calorie, low-salt, low-protein diet, with one peritoneal dialysis and subsequent haemodialyses (twin coil) through a Scribner arteriovenous shunt (Fig. 1). Prednisone $(60 \mathrm{mg} / \mathrm{day}$ reducing to $30 \mathrm{mg} /$ day after three weeks) was given by mouth from the third day. After six days and three dialyses the urinary output began to rise, and after two weeks was 2 litres/day. At the beginning of this phase the serum cholesterol was $700 \mathrm{mg} / 100 \mathrm{ml}$.

Royal Devon and Exeter Hospital, Exeter EX1 1 PQ

G. H. HALL, M.D., Consultant Physician

R. A. CALDWELL, M.D., Consultant Pathologist

C. SHALDON, M.CH., Consultant Surgeon

P. G. BISSON, M.B., Medical Registrar
One month after admission the urine output decreased and uraemia and hypertension (175/135) returned, with epileptic fits, papilloedema, and retinal exudates and haemorrhages. Dialysis failed to control the hypertension, retinopathy, and fits. The platelet count remained below $150,000 / \mathrm{mm}^{3}$ and the haemoglobin fell to $7.5 \mathrm{~g} / 100$ $\mathrm{ml}$. Bilateral nephrectomy was performed on 1 October 1969 and thrice-weekly dialysis instituted. In October 1970 a kidney from the patient's father was transplanted into the patient by Professor R. Y. Calne at Cambridge. After the nephrectomy the blood pressure was easily controlled, the serum cholesterol levels ranged between 282 and $344 \mathrm{mg} / 100 \mathrm{ml}$, and platelet counts exceeded $300,000 / \mathrm{mm}^{3}$. No evidence of lipidosis was observed by slit-lamp examination of the cornea or on bone marrow examination.

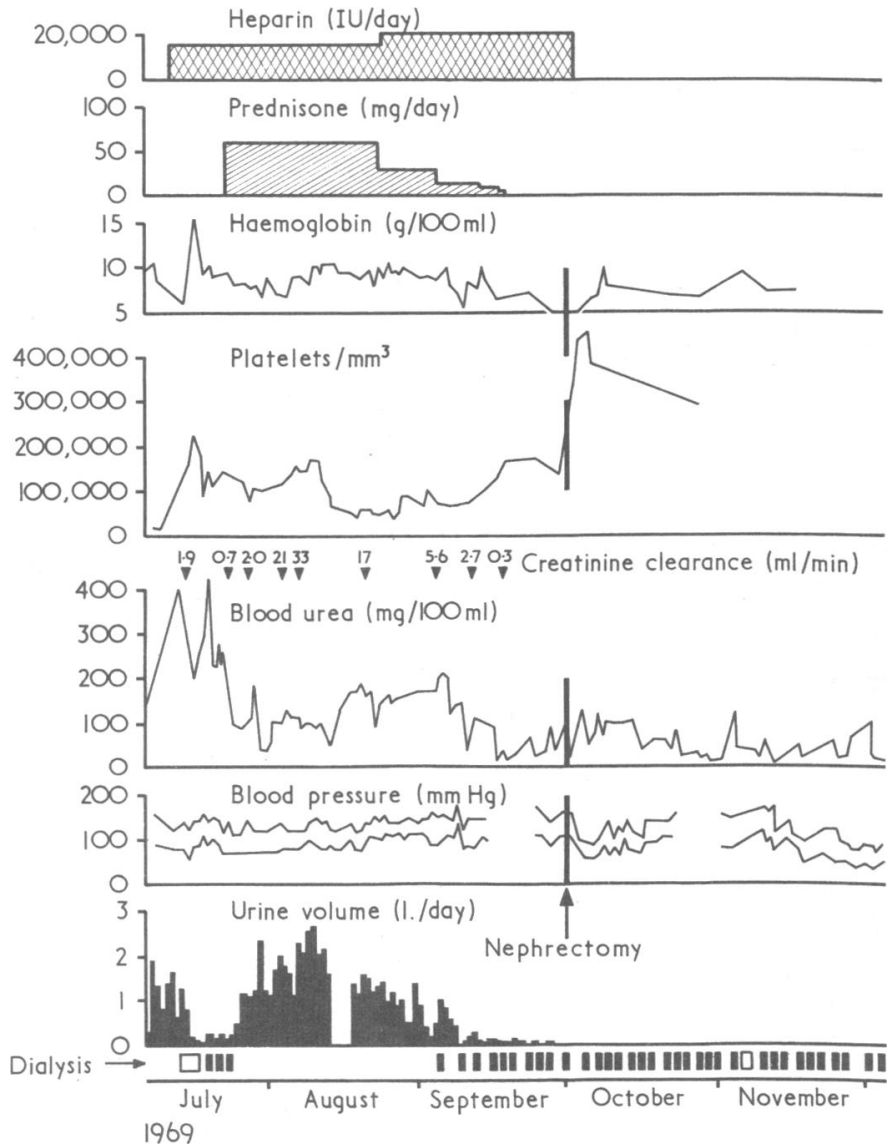

FIG. $1-$ Clinicopathological course. $\square=$ Peritoneal dialysis Haemodialysis through arteriovenous shunt. 